\title{
The European Pollen Database: Research tool and community
}

\author{
Thomas Giesecke1, J.-L. de Beaulieu² and M. Leydet-Barbier²
}

Aix-en-Provence, France, 1-3 June 2016

Open-access paleo databases are of the utmost importance to arrive at a regional, continental, or global understanding of long-term processes and investigate past dynamics of Earth systems. The European Pollen Database (EPD), created alongside the North American Pollen Database more than 25 years ago, serves as the base for numerous analyses of climate, vegetation and land-cover change, while also being an important data repository and educational tool (Fyfe et al. 2009). To function as an upto-date research tool, the database requires both the submission of new pollen data from the community as well as data stewardship and development of the database. The database is a community-wide effort, but there is an inherent risk of a division between data producers and data users. To overcome this separation and to generate new momentum in the development of the database, we called for an open EPD meeting and training workshop. Co-funded by PAGES, it attracted 126 paleoecologists, at all career stages, from 24 countries.

The meeting consisted of plenary lectures, training workshops, and group and plenary discussions. The lectures illustrated different research fields that use the database, such as climate and land-cover reconstructions (J. Guiot and M.-J. Gaillard), archeology (R. Fyfe), last glacial vegetation change (M F. Sanchez Goñi), nature conservation (R. Bradshaw), and the postglacial spread of plants (T. Giesecke). Lectures also addressed interactions with the Global Charcoal Database (B. Vannière \& D. Colombaroli), problems developing age models beyond the radiocarbon timescale (C. Tzedakis), and the new database infrastructure Neotoma (E. Grimm).

Seven parallel training workshops introduced participants to numerical problems in paleodata analyses and representation: (i) the data management and graphing software Tilia and its interaction with Neotoma (E. Grimm); (ii) the use of the modern surface sample dataset in quantitative reconstructions (B. Davis \& M. Zanon); (iii) quantitative vegetation reconstructions using the Landscape Reconstruction Algorithm (P. Kuneš \& M. Theuerkauf); (iv) charcoal software and database (B. Vannière \& W. Finsinger); (v) working with the EPD using the data analysis software " $R$ " (A. Seddon \& J. Chipperfield); and (vi) age modeling ( $T$. Giesecke). Another workshop was dedicated to the identification of non-pollen-palynomorphs (B. Dietre \& S. Wolters), which is a field of active development in Quaternary palynology. All workshops were well received by participants, who wished they could be organized on a regular basis.

Group and plenary discussions focused on how to improve the database and make it more accessible to other communities, and we reviewed and simplified the rules and

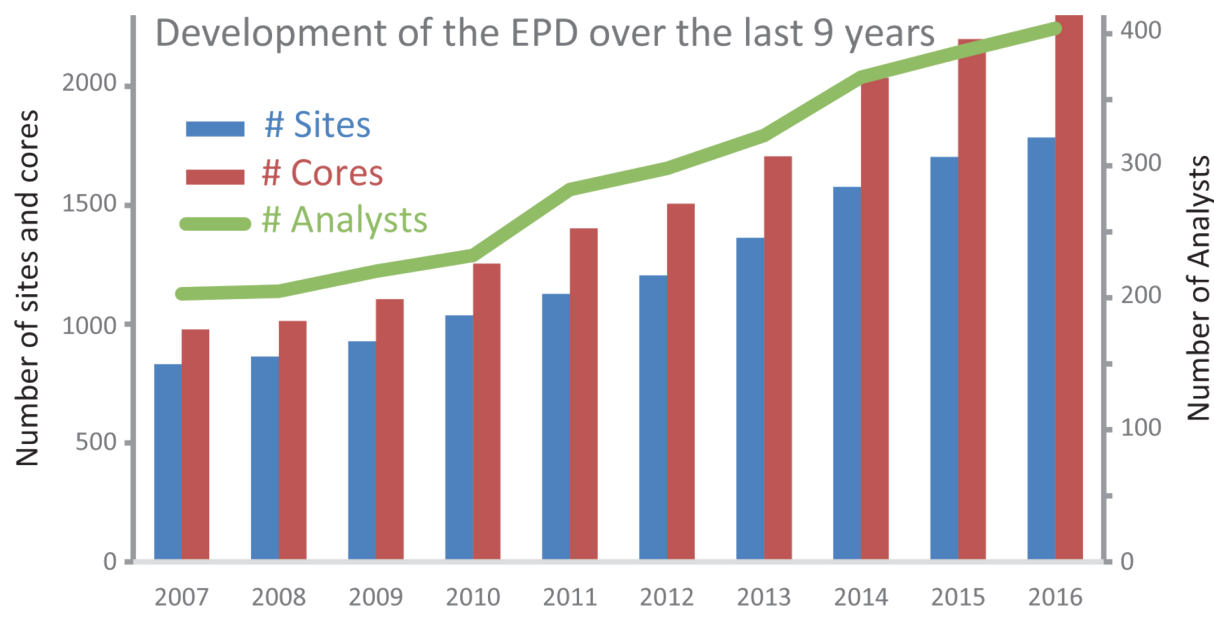

Figure 1: Development of the European Pollen Database since the open meeting in 2007. The number of sites and cores has doubled over the last nine years. regulations. We also reviewed and reorganized the following EPD working groups:

The Taxonomy working group, coordinated by Steffen Wolters, keeps track of synonym names in the database and is developing a hierarchical system based on morphology. Future activities will include non-pollen-palynomorphs.

The Chronologies working group has produced standardized age models for over 800 sites (Giesecke et al. 2014). Coordinated by Thomas Giesecke, the group aims to provide the same type of models in addition to bayesian age models for the recently submitted sites.

Coordinated by Basil Davis, the Surface Samples working group, which compiled a new European dataset of surface sample data (Davis et al. 2013), will work on expanding this dataset.

The group on Community Outreach is now coordinated by Graciela Gil-Romera. This group will use social media to improve visibility, prepare educational packages for the general public and organize training workshops for the EPD community.

The new Quantitative Tools working group, coordinated by Alistair Seddon, was formed to focus on R and GIS applications. Plus, Petr Kuneš heads up another new group, Former Interglacials, which aims to organize and promote datasets that go beyond the radiocarbon time scale.

Be involved! For further news and information on how to contribute, go to: www. europeanpollendatabase.net

\section{AFFILIATIONS}

'Department of Palynology and Climate Dynamics, University of Göttingen, Germany

${ }^{2}$ Institut Méditerranéen de Biodiversité et d'Ecologie marine et continentale, Aix-Marseille Université, Aix-en-Provence, France

\section{CONTACT}

Thomas Giesecke: thomas.giesecke@biologie.uni-goettingen.de

\section{REFERENCES}

Davis BAS et al. (2013) Veget Hist Archaeobot 22: 521-530 Fyfe RM et al. (2009) Veget Hist Archaeobot 18: 417-424 Giesecke T et al. (2014) Veget Hist Archaeobot 23: 75-86 